DOI: https://doi.org/10.24867/02CG01Vucic

\title{
UPOREDNA ANALIZA SEIZMIČKOG OBLIKOVANJA STUBOVA MOSTA PREMA STARIM I NOVIM PROPISIMA
}

\section{A COMPARATIVE ANALYSIS OF THE SEISMIC DESIGN OF THE BRIDGE ACCORDING TO OLD AND NEW REGULATIONS}

\section{Oblast - GRAĐEVINARSTVO}

Kratak sadržaj - U ovom radu prikazana je uporedna analiza seizmičkog oblikovanja stubova mosta prema starim i novim propisima.
\end{abstract}

Stefan Vučić, Andrija Rašeta, Fakultet tehničkih nauka, Novi Sad
Ključne reči: Most, Armiranobetonski nadvožnjak, Seizmička analiza mostova

Abstract - This paper presents a comparative analysis of seismic design of bridge pillars according to old and new regulations.

Keywords: Bridge, Reinforced concrete overpass, Seizmic analysis bridge

\section{UVOD}

Mostovi, građevine koje svojom lepotom mame poglede prolaznika i koje ujedno imaju ulogu u povezivanju ljudi. Kako kroz istoriju, tako i danas, mostovi predstavljaju vrhunac graditeljstva.

Kako je građevinarstvo napredovalo, tako su se i propisi za projektovanje mostova menjali i dopunjavali. Danas se velika pažnja posvećuje projektovanju seizmički otpornih konstrukcija, što je proisteklo iz dugogodišnjeg iskustva i praćenja zemljotresnog dejstva na objekte. Shodno tome, u ovom radu će biti opisane razlike seizmičkog oblikovanja stubova mosta prema Pravilniku za beton i armirani beton iz 1987. godine i Evrokoda 8-2.

\section{PRAVILNIK IZ 1987. GODINE}

Ovim pravilnikom propisani su tehnički normativi za projektovanje i proračun inženjerskih objekata u seizmički aktivnim područjima [4].

\subsection{Kategorije značaja}

Mostovi se prema ovom pravilniku svrstavaju u dve kategorije značaja, i to:

- raspona $L \geq 50,0 \mathrm{~m}$ ili visine stubova $H \geq 30,0 \mathrm{~m}$

- raspona $\mathrm{L}<50,0 \mathrm{~m}$ ili visine stubova $\mathrm{H}<30,0 \mathrm{~m}$.

\subsection{Seizmički proračun}

Seizmički proračun konstrukcije se vrši najmanje u dva upravna pravca i to:

- Metoda spektralne analize

- Metoda dinamičke analize

\section{NAPOMENA:}

Ovaj rad proistekao je iz master rada čiji mentor je bio doc. dr Andrija Rašeta.
Takođe uvode se i dva projektna tipa zemljotresa, i to: - Z1 - projektni zemljotres je najači očekivani zemljotres koji može pogoditi objekat za vreme korišćenja, može se dogoditi jednom u 100 godina s verovatnoćom pojave od $70 \%$ za sve objekte van kategorije.

- Z2 - projektni zemljotres je onaj zemljotres koji može pogoditi objekat u bilo kom vremenskom periodu i koji se može dogoditi jednom u 1000 godina s verovatnoćom pojave od $70 \%$.

\subsubsection{Metoda spektralne analize}

Metodom spektralne analize seizmičke sile se pri $i$-tom obliku oscilovanja u tački $k$ određuju na sledeći način:

$$
S_{i k}=K_{s} * \beta_{i} * \eta_{i k} * \psi * G_{k}
$$

$K_{S}$ - seizmički koeficijent

$\beta_{i}$ - koeficijent dinamičnosti

$\eta_{i k}$ - koeficijent koji zavisi od sopstvenog oblika oscilovanja konstrukcije

$\psi$ - koeficijent redukcije usled duktilnosti

$G_{k}$ - težina konstrukcije koncentrisana u tački $k$

\subsubsection{Metoda dinamičke analize}

Ova analiza sprovodi se radi utvrđivanja ponašanja konstrukcije u elastičnom i neelastičnom području rada. Ovom analizom utvrđuje se granično stanje naprezanja i deformacija konstrukcije za delovanje zemljotresa tipa Z1 i Z2 i utvrđuje se prihvatljivi stepen oštećenja koji može nastati prilikom maksimalnog očekivanog zemljotresa. Seizmički parametri određuju se za konkretnu lokaciju na osnovu učestalosti zemljotresa i eksploatacionog perioda. Ako ne postoje podaci o zemljotresnom dejstvu na datoj lokaciji, onda se više tipova zemljotresnog dejstva svodi na isti intenzitet (po parametrima: maksimalno ubrzanje, maksimalna brzina) i za svaki sračunava spektar odgovora. Na osnovu ovih spektara formira se srednji spektar koji se dalje koristi u proračunu [2].

\subsubsection{Pravila i detalji armiranja}

Ovim pravilnikom se ne definišu posebni zahtevi za pravila i detalje armiranja.

\section{EVROKOD 8-2}

Deo 2 Evrokoda 1998 (EN 1998-2) sadrži posebne zahteve za projektovanjem seizmički otpornih mostova. Kod mostova seizmičko delovanje se najčešće prihvata stubovima, te se njima pridaje posebna pažnja pri proračunu i oblikovanju. Ležišta i uređaji za seizmičku izolaciju imaju veliku ulogu u prenosu seizmičkog dejstva, te se njima mora posvetiti posebna pažnja [3]. 


\subsection{Kategorije značaja}

Prema Evrokodu 1998-2 definisani su sledeće kategorije značaja mostova:

- Razred važnosti I - ovo je najniži razred važnosti i obuhvata mostove koji nisu kritični po pitanju prometa saobraćaja

- Razred važnosti II - ovo je sredni razred važnosti

- Razred važnosti III - ovaj razred obuhvata mostove velike važnosti za odvijanje saobraćaja, pogotovo nakon seizmičkog dejstva.

\subsection{Seizmički proračun}

Dva načina seizmičkog proračuna mostova su:

- Duktilno ponašanje

- Ograničeno duktilno ponašanje (slika 1.)

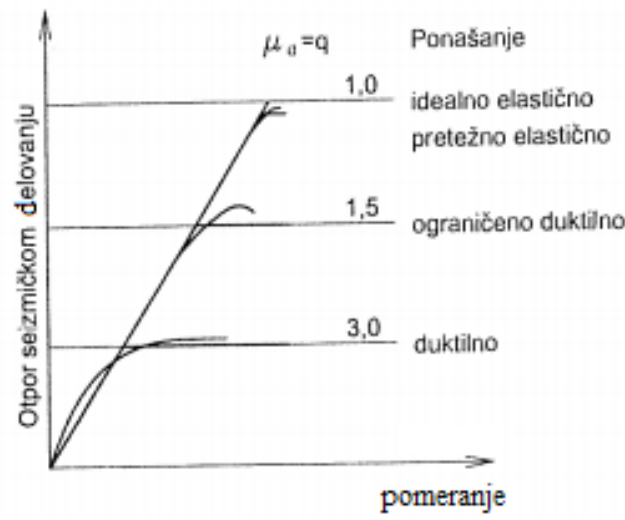

Slika 1. Duktilnost konstrukcije [1]

\subsubsection{Duktilno ponašanje}

U područjima umerene i visoke seizmičnosti obično se primenjuje ovaj način projektovanja mostova. Ovo je obrazloženo velikom mogućnošću ovakvih konstrukcija za disipiranjem velike količine seizmičke energije i formiranjem plastičnih zglobova. Plastični zglobovi se najčešće formiraju u stubovima zato što su oni najznačajniju prenosnici u prenostu seizmičkog dejstva.

\subsubsection{Ograničeno duktilno ponašanje}

Ovaj način projektovanja mostova ne zahteva područija sa značajnom redukcijom krutosti i disipiranjem seizmičke energije. Ovim načinom projetovanja ne zahteva se idealno elastično ponašanje konstrukcije, već se faktorom ponašanja $q \leq 1,50$ obezbeđuje delimično duktilno ponašanje.

Ovakav faktor ponašanja opisuje se razlikom između projektovane i stvarne čvrstoće konstrukcije.

Za mostove sa kritičnim konfiguracijama i za mostove gde se ne može obezbediti pouzdano armiranje plastičnih zona, konzervativno se može usvojiti faktor ponašanja $q=1,00$ i time obezbediti elastično ponašanje konstrukcije pri seizmičkom delovanju.

\subsection{Pravila i detalji armiranja}

\subsubsection{Maksimalno rastojanje podužnih šipki armature}

Definisano je sledećim izrazom:

$$
s_{T} \leq \min \left(\frac{b_{\min }}{3}, 200 \mathrm{~mm}\right)
$$

$b_{\text {min }}$ - minimalna dimenzija stuba

\subsubsection{Dodatno ojačanje uzemgijama}

U područiju gde bezdimenzionalna aksijalna sila prekoračuje sledeću vrednost, neophodno je predvideti ojačanje preseka dodtatnim uzengijama kako ne bi došlo do krtog loma pre nego što naprezanje glavne podužne armature dosegne granicu razvlačenja.

$$
\eta_{k}=\frac{N_{E d}}{A_{c} * f_{c k}}>0,08
$$

$N_{E d^{-}}$proračunska vrednost aksijalne sile u stubu usled seizmičke kombinacije

$A_{c}$ - površina betonskog dela preseka stuba

$f_{c k}$ - karakteristična vrednost čvrstoće betona na pritisak

Ovo ojačanje nije neophodno u slučajevima kada:

- Koeficijent duktilnosti sračunat preko zakrivljenosti ima sledeće vrednosti:

$\mu_{\emptyset}=13-$ za duktilne mostove

$\mu_{\emptyset}=7$ - za mostove sa ograničenom duktilnošću

- Odnosno ako maksimalna pritisna deformacija betona ne prekoračuje vrednost $\varepsilon_{c u, 2}=0,35 \%$

U slučaju visokog pritiska ojačanje uzengijama treba sprovesti sve dok je pritisak u betonu veći od $0,50 \varepsilon_{c u, 2}$.

\subsubsection{Visina plastičnog zgloba}

Utezanje pritisnutog dela preseka treba da se proteže celom visinom plastičnog zgloba i izvan nje. Dužina plastičnog zgloba zavisi od podužne sile i sračunava se na sledeći način:

- Ako je bezdimenzionalna vrednost aksijalne sile:

$$
\eta_{k}=\frac{N_{E d}}{A_{c} * f_{c k}} \leq 0,30
$$

Računska vrednost visine plastičnog zgloba jednaka je većoj vrednosti od:

$\mathrm{L}_{\mathrm{h}}=$ visina preseka stuba upravno na osu zgloba

$\mathrm{L}_{\mathrm{h}}=$ udaljenost od mesta maksimalnog momenta pa do mesta gde je moment manji za $20 \%$

- Ako je bezdimenzionalna vrednost aksijalne sile:

$$
0,60 \geq \eta_{k}=\frac{N_{E d}}{A_{c} * f_{c k}}>0,30
$$

Računska dužina plastičnog zgloba proračunata preko prethodnih formula uvećava se za $50 \%$.

\subsubsection{Sprečavanje izvijanja podužne armature}

Kako bi se sprečilo izvijanje podužne armature $u$ područiju plastičnog zgloba usled cikličnog naprezanja, glavnu podužnu armaturu bi trebalo pridržati poprečnom koja se postavlja sa spoljašnje strane kako bi sprečila izbočavanje podužne armature.

Poprečna armatura postavlja se na rastojanju koje nije veće od:

gde je:

$$
s_{L} \leq \delta * d_{b L}
$$

$$
5 \leq \delta=2,5 *\left(\frac{f_{t k}}{f_{y k}}\right)+2,25 \leq 6
$$

$S_{L}$ - maksimalno rastojanje poprečne armature

$d_{b L^{-}}$prečnik podužne armature

$f_{t k}$ - karakteristična vrednost zatezne čvrstoće čelika

$f_{y k}$ - proračunska vrednost zatezne čvrstoće čelika 


\subsubsection{Količina uzengija za ojačanje u kritičnoj oblasti}

Količina uzengija definisana je preko mehaničkog zapreminskog koeficijenta armiranja:

$$
\omega_{w d}=\rho_{w} * \frac{f_{y d}}{f_{c d}}
$$

$\omega_{w d, c}-$ mehanički zapreminski koeficijent armiranja $\rho_{w}$ - geometrijski koeficijent armiranja

\subsubsection{Količina uzengija van kritične oblasti}

Van kritičnih oblasti ne sme se naći manja količina armature od $50 \%$ one koja se nalazi u kritičnoj zoni. Drugi zahtev proizilazi iz potrebe proračuna, a treći je minimalna količina čija se vrednost računa na sledeći način:

- za pravougaone preseke:

$$
\omega_{w d, r} \geq \max \left(\omega_{w d, r e q}, \frac{2}{3} \omega_{w d, \min }\right)
$$

- za kružne preseke:

$$
\omega_{w d, c} \geq \max \left(1,4 \omega_{w d, r e q}, \omega_{w d, \min }\right)
$$

gde je:

$$
\omega_{w d, r e q}=\frac{A_{c}}{A_{c c}} * \lambda \eta_{k}+0,13 * \frac{f_{y d}}{f_{c d}}\left(\rho_{L}-0,01\right)
$$

Tabela 1. Minimalne vrednosti za $\lambda i \omega_{w, \min }$

\begin{tabular}{|c|c|c|}
\hline Seizmičko ponašanje & $\lambda$ & $\omega_{w, \min }$ \\
\hline Duktilno & 0,37 & 0,18 \\
\hline Ograničeno duktilno & 0,28 & 0,12 \\
\hline
\end{tabular}

$\omega_{w d, c^{-}}$mehanički zapreminski koeficijent armiranja za

$$
\text { kružne preseke }
$$

$A_{c}$ - površina betonskog dela preseka

$A_{c c}$-površina betonskog jezgra preseka

$\lambda$ - koeficijet dat u tabeli 1 .

$\eta_{k}$ - koeficijent aksijalne sile

$f_{c d}$ - proračunska vrednost čvrstoće betona na pritisak

$f_{y d}$ - proračunska vrednost čvrstoće uzengija

$\rho_{L}-$ geometrijski koeficijent armiranja

\subsubsection{Armiranje stubova za udar vozila}

Ako je stub dimenzionisan na udar vozila, neophodno je da se uzdužna armatura do visine od $2 \mathrm{~m}$ iznad kolovoza ugrađuje u dva reda, i to bez nastavljanja u toj oblasti. Unutrašnja i spoljašnja armatura na toj visini obuhvataju se uzengijama najmanjeg prečnika $12 \mathrm{~mm}$ [1]. (slika 2.)
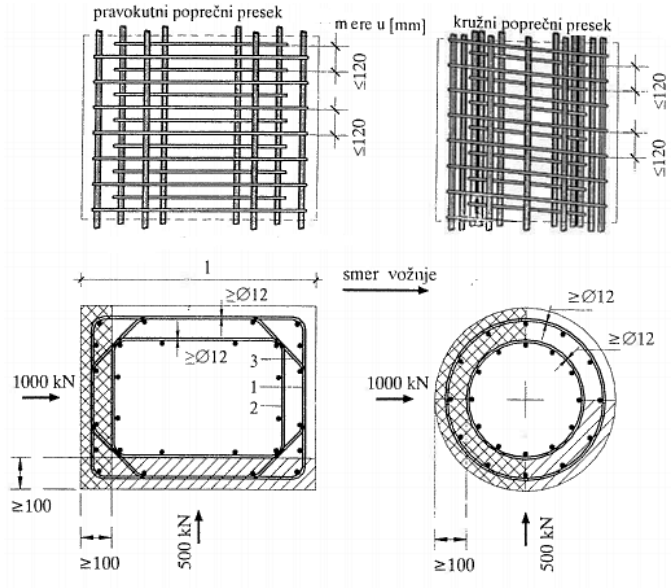

šrafirano područje - moguće odlamanje betona

Slika 2. Armiranje stubova za udar vozila [1]

\subsubsection{Ležišta i seizmički graničnici}

Kod grednih mostova spoj rasponske konstrukcije i oslonca treba proračunati na seizmičko pomeranje kako ne bi došlo do pada rasponske konstrukcije sa ležišta.

Treba predvideti dovoljnu dužinu naleganja rasponske konstrukcije na pomična ležišta kako ne bi došlo do njihovog pada, ili obezbediti seizmičke graničnike koji će pomeranja držati u prihvatljivim granicama [1]. (slika 3.)

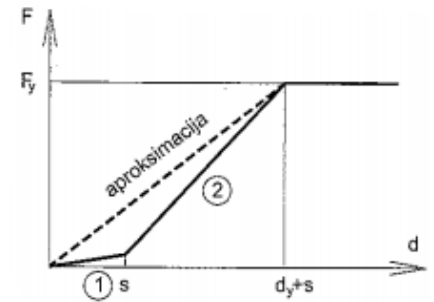

s - pomeranje popuštanje graničnika $\mathrm{d}_{y}$ - pomeranje.popuštanje armature $u$ potporama

1- krutost ležaja

2 - krutost potpora

Slika 3. Zavisnost pomeranja konstrukcije od sile [1]

Pokretna ležišta treba osigurati od oštećenja na način da se proračuna maksimalno seizmičko pomeranje konstrukcije i na osnovu tog pomeranja odabere adekvatno ležište. Seizmičko pomeranje računa se na sledeći način:

$$
d_{E d}=d_{E}+d_{G} \pm d_{T s}
$$

$d_{E}$ - računski seizmičko pomeranje $d_{E}= \pm d_{E d} * q$

$d_{G}$-pomeranje usled skupljanja, tečenja i prednaprezanja $d_{T s}$ - pomeranje usled promene temperature

\subsubsection{Minimalna dužina naleganja}

Ova dužina osigurava da usled seizmičkog dejstva ne dođe do pada konstrukcije sa ležišta.

$$
l_{o v}=l_{m}+d_{e g}+d_{e s}
$$

$l_{m}$ - minimalna dužina podupiranja; $>40 \mathrm{~cm}$.

$d_{e g}$ - efekti pomeranja dva dela usled diferencijalnog seizmičkog pomeranja tla:

$$
d_{e g}=\frac{L * v_{g}}{c_{p}} \leq 2 d_{g}
$$

$L$ - efektivna dužina rasponske konstrukcije

$v_{g}$ - maksimalna brzina tla sračunata kao $v_{g} / a_{g}$ (tabela 2.)

Tabela 2. Vrednosti $v_{g} / a_{g}$

\begin{tabular}{|c|c|c|c|}
\hline Klasa tla & A & B & C \\
\hline$v_{g} / a_{g}(s)$ & 0,090 & 0,135 & 0,160 \\
\hline$d_{g} / a_{g}\left(s^{2}\right)$ & 0,060 & 0,090 & 0,108 \\
\hline
\end{tabular}

$c_{p}$ - procenjena brzina širenja talasa u tlu (tabela 3 .)

Tabela 3. Vrednosti $c_{p}$

\begin{tabular}{|c|c|}
\hline Klasa tla & $c_{p}(\mathrm{~m} / \mathrm{sec})$ \\
\hline Stena & 1000 \\
\hline $\begin{array}{c}\text { Gusto granulisano tlo ili tvrda prekonsolidovana } \\
\text { glina }\end{array}$ & 500 \\
\hline Pesak srednje gustine & 300 \\
\hline Sredna do meka glina & 150 \\
\hline
\end{tabular}

$d_{g}$ - računska vrednost maksimalnog pomeranja tla koja se računa preko izraza:

$$
d_{g}=0,05 * a_{g} * S * T_{C} * T_{D}
$$

$d_{e s}$ - efektivno seizmičko pomeranje oslonaca, nastao deformisanjem konstrukcije, a računa se na sledeći način:

- za rasponske konstrukcije koje su sa stubovima vezane preko nepomerljivih ležišta ili monolitno vezane:

$d_{e s}=d_{E d}$.

- za rasponske konstrukcije koje su sa stubovima vezane preko seizmičkih graničnika: $d_{e s}=d_{E d}+s$. 


\section{ZAKLJUČAK}

Pravilnik za beton $i$ armirani beton iz 1987. godine je jednostavan za upotrebu i uključuje najvažnije uticajne faktore pri proračunu seizmičkih sila. Nedostaci su mu što ne daje jasno značenje pojedinih seizmičkih parametara $\left(K_{s}, \beta_{i}\right)$ i ne uzima u obzir uticaje nelinearnog ponašanja (duktilnost) sistema na veličinu seizmičkih sila (faktor duktilnosti se usvaja $\mu_{p}=4,0$ bez obzira na vrstu konstrukcije), i ne definiše detalje armiranja nosivih elemenata. Globalno gledano može se uočiti sličnost osnovnih seizmičkih koeficijenata prema Pravilniku i Evrokodu, ali Evrokod ipak daje znatno veći tzv. Ukupni seizmički koeficijent [1].

Evrokod 8 je proizvod savremenih, eksperimentalnih teorijskih i praktičnih znanja i iskustava u ovoj oblasti. Temelji se na duktilnom nelinearnom ponašanju mostova pri zemljotresu koje u proračun implementira kroz pojednostavljene modele proračuna. Poteškoće ovog postupka je određivanje faktora ponašanja konstrukcije $q$ koji predstavlja ulazni podatak i od koga bitno zavisi veličina seizmičkih sila, a kojim se mora predvideti duktilno ponasanje konstrukcije odnosno njena sposobnost da primi seizmičke sile bez krtih lomova (da izvrši disipaciju seizmičke energije) [3].

Kod duktilnijih konstrukcija biće potrebno manje glavne armature a više poprečne armature u kritičnim zonama kako bi se obezbedilo duktilno ponašanje i programirano formiranje plastičnih zglobova. Dok sa druge strane kod kojih se seizmička sila prihvata elastičnim ponašanjem konstrukcije, proračun zahteva veću količinu glavne (podužne) armature.

\section{LITERATURA}

[1] Jure Radić, Ana Mandić, Goran Puž: „Konstruiranje mostova“, Zagreb 2005

[2] Jure Radić i suradnici: „Betonske konstrukcijepriručnik"; Zagreb 2006

[3] Eurocode 8 (Part 2) - Design of structures for earthquake resistance-Bridges

[4] Pravilnik o tehničkim normativima za projektovanje i proračun inženjerskih obekata u seizmički aktivnim područjima.

\section{Kratka biografija:}

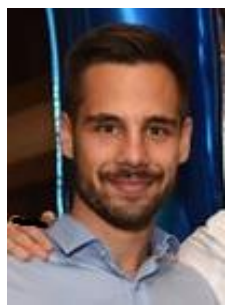

Stefan Vučić rođen je u Kraljevu 1994. god. Diplomirao je na Fakultetu tehničkih nauka u Novom Sadu 2017. godine. Master rad na

Fakultetu tehničkih nauka iz oblasti

Betonskih mostova brani 2018.god.

kontakt: vucke94@gmail.com

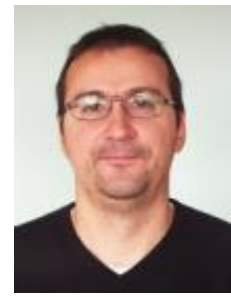

Doc. dr Andrija Rašeta rođen je u Novom Sadu 1973. Diplomirao je na Fakultetu tehničkih nauka u Novom Sadu -

Građevinski odsek 2002. godine. Magistrirao je na Građevinskom fakultetu Univerziteta u Beogradu 2010. godine. Doktorirao je na Fakultetu tehničkih nauka u Novom Sadu 2014. god., a od 2002 radi na Fakultetu tehničkih nauka. 